Journal of Clinical Investigation

Vol. 42, No. 2, 1963

\title{
THE MECHANISM OF PULSUS PARADOXUS DURING ACUTE
} PERICARDIAL TAMPONADE *

\author{
By RICHARD J. GOLINKO, $\dagger$ NEVILLE KAPLAN, AND ABRAHAM M. RUDOLPH $\ddagger$
}

(From the Departments of Pediatrics and Radiology, Albert Einstein College of Medicine, New York, N. Y.)

(Submitted for publication June 5, 1962; accepted November 1, 1962)

A small fall in systemic arterial pressure during inspiration has been observed to occur in normal individuals. The term "pulsus paradoxus" has been applied to an accentuation of this phenomenon as it occurs in patients with pericardial tamponade. The mechanism for this increased respiratory variation of systemic arterial pressure during pericardial tamponade has interested many observers. Several explanations, based on observations in experimental animals and man, have been proposed to explain the hemodynamic alterations responsible for pulsus paradoxus. Wood (1) has suggested that with the descent of the diaphragm during inspiration, traction is applied to the pericardium, raising intrapericardial pressure and interfering with left ventricular filling. Dornhorst, Howard, and Leathart (2), using an experimental model, claimed that filling of the right ventricle during inspiration raised intrapericardial pressure, which then interfered with left ventricular filling. Much earlier, Katz and Gauchat (3) demonstrated a decrease in the pressure gradient between superior vena cava and right atrium during inspiration. On the basis of this observation, they postulated that a similar mechanism on the left side could explain the paradoxical pulse in pericardial tamponade.

Recently, Sharp and co-workers (4) had an opportunity to perform an acute tamponade experiment in a man who required permanent cannulation of the pericardial sac. Their data, not based on actual measurement of pulmonary venous and left atrial pressures, indicated that the mechanism suggested by Katz and Gauchat (3) for the ex-

\footnotetext{
* Supported by grant H-5686 from the U. S. Public Health Service and a grant-in-aid from the American Heart Association; presented in part at the American Heart Association meetings, Miami, Fla., October, 1961. $\dagger$ Research Fellow, U. S. Public Health Service. $\ddagger$ Established Investigator, American Heart Associa-
} tion. aggerated respiratory variation in systemic arterial pressure probably also applied to man.

Since the pulmonary veins are thin-walled structures highly susceptible to fluctuations in intrathoracic pressure, we considered a disturbance of the gradient between pulmonary venous and left atrial pressure as a possible explanation for the fundamental circulatory defect responsible for the exaggerated respiratory variation in pulse that is characteristic of pericardial tamponade. This study was designed to investigate this possibility and thereby further clarify the dynamics of pulsus paradoxus.

\section{METHODS}

Five mongrel dogs weighing 15 to $20 \mathrm{~kg}$ were anesthetized with intravenous sodium pentobarbital, $30 \mathrm{mg}$ per kg. An endotracheal tube with rubber cuff was inserted and positive-pressure ventilation was maintained by means of a Harvard respiratory pump. A positive end-expiratory pressure of $3 \mathrm{~cm}$ water was maintained to prevent collapse of the lungs when the chest was opened.

The chest was opened by a transverse thoracotomy in the fourth left intercostal space. Through a small opening in the pericardium, polyvinyl catheters $(0.070$ inch outside diameter, 0.038 inch inside diameter) were inserted into the left atrium through the appendage and into the left ventricle. A no. 14 thin-walled needle was inserted in the left lower pulmonary vein beyond the left atrial junction through a purse-string suture. A soft polyvinyl catheter $(0.052$ inch outside diameter, 0.027 inch inside diameter) was inserted through the needle, which was then removed over the catheter. The tip of the catheter was placed in the "free" left lower pulmonary vein 1.5 to $2 \mathrm{~cm}$ beyond its junction with the left atrium and secured in position. Before the pericardium was closed, two additional polyvinyl catheters were fixed in position in the pericardial space for measurement of intrapericardial pressure and for infusion and withdrawal of fluid.

The pericardium was then closed and examined carefully for any leakage. Intrathoracic pressure was measured with either an intraesophageal balloon or a polyvinyl catheter located in the intrapleural space. All catheters were exteriorized and the chest closed. Pres- 

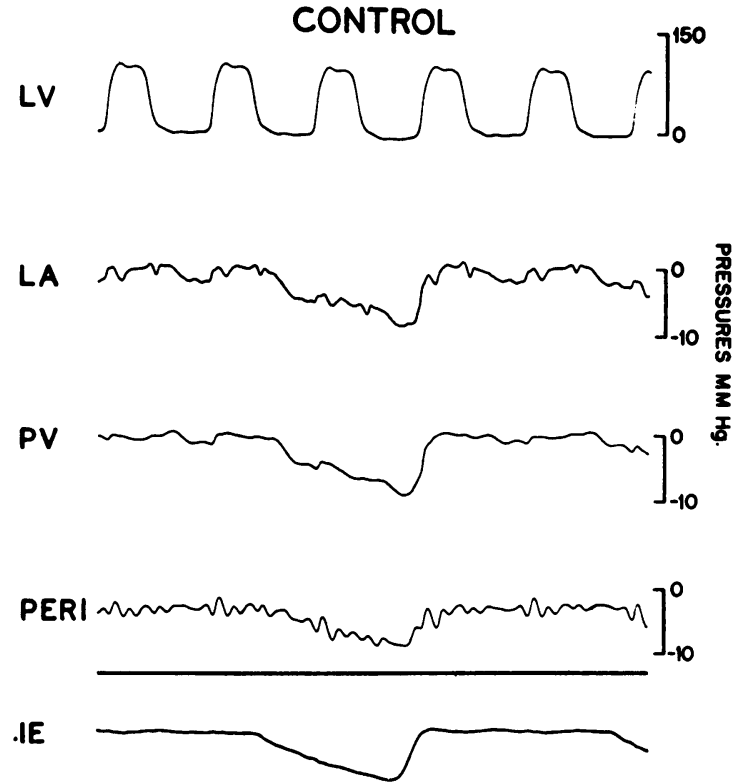

Fig. 1. THE EFFeCt OF NORMAL RESPIRATION ON LEFT VENTRICULAR, LEFT ATRIAL, PULMONARY VENOUS, AND PERICARDIAL PRESSURES IN THE CONTROL ANIMAL.

sures were measured by means of Statham $P$ 23D pressure transducers and continually recorded on a Grass direct-writing polygraph. In two experiments, cardiac output was determined by indicator dilution techniques (5) using indocyanine green. In one additional experiment, phasic aortic flow was measured by a gated, sinewave, electromagnetic flowmeter of the Kolin type with the cuff flow transducer placed around the descending aorta. After the chest was closed, pressures in the various segments were recorded simultaneously and the effects of the normal respiratory pattern observed. In order to exaggerate the respiratory changes, the effect of increased negative ventilation was also studied by use of a two-way respiratory valve, which permitted graded occlusion of the inspiratory side of the valve. All observations were made during varying degrees of pericardial tamponade produced by infusion and withdrawal of normal saline. The amounts of saline infused to produce tamponade varied from 100 to $180 \mathrm{ml}$, depending on the size of the animal.

In two further experiments, pulmonary venous and inferior vena caval flow rates were studied by means of cineangiography. Small droplets of iodinized oil (Lipiodol) were injected into the inferior vena cava and pulmonary vein, and the rate and direction of flow were observed during the respiratory phases with and without pericardial tamponade.

\section{RESULTS}

The production of pulsus paradoxus by introduction of fluid into the pericardial space was dem- onstrated by measurement of systemic arterial or left ventricular pressure. A small respiratory fluctuation in left ventricular systolic pressure was noted with a slightly lower pressure in inspiration and a greater pressure in expiration with an average variation of 2 to $8 \mathrm{~mm} \mathrm{Hg}$ in the control animal (Figure 1). During pericardial tamponade, a significant, increased, respiratory fluctuation of left ventricular systolic pressure developed averaging 15 to $22 \mathrm{~mm} \mathrm{Hg}$ (Figure 2). In several instances, when the degree of pericardial tamponade was extreme and systemic pressure markedly reduced, the pulsus paradoxus disappeared.

Analysis of the aortic flow tracings showed that the pressure phenomena were directly related to changes in blood flow so that any fall in left ventricular systolic pressure was accompanied by a corresponding reduction in aortic blood flow. Cardiac output in the normal animal averaged 4.7 $\mathrm{L}$ per minute, but was reduced during pericardial tamponade to $1.7 \mathrm{~L}$ per minute.

Intrapericardial pressure. In the control animal, intrapericardial pressure levels were close to those of intrathoracic pressures and showed wide fluctuation with respiration (Tables I and II, Figure 1). During the period of increasing pericardial tamponade, intrapericardial pressure rose sharply after each increment of fluid. This

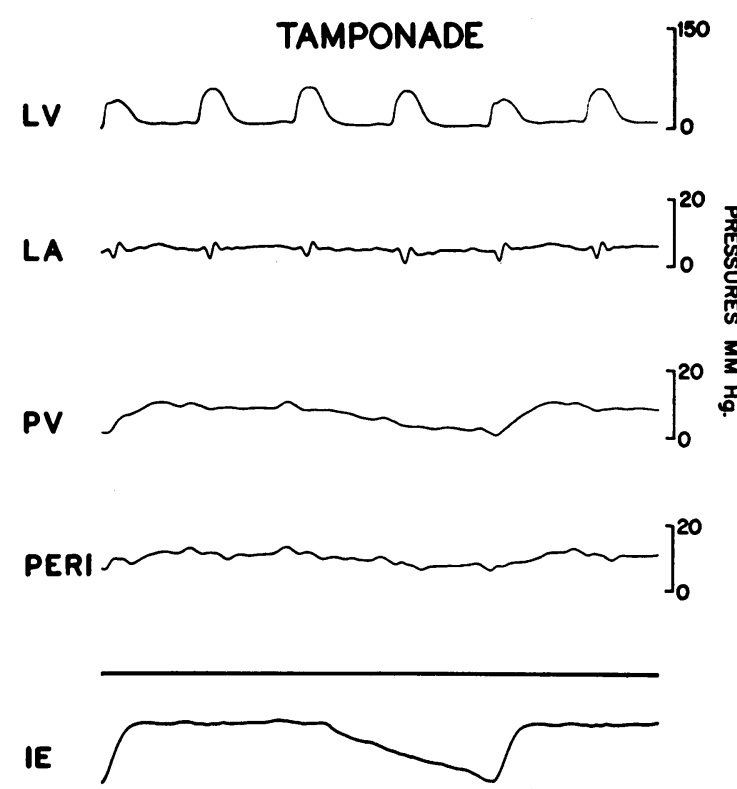

Fig. 2. THE EFFECT OF NORMAL RESPIRATION ON LEFT VENTRICULAR, LEFT ATRIAL, PULMONARY VENOUS, AND PERICARDIAL PRESSURES DURING PERICARDIAL TAMPONADE. 
TABLE I

Average pressures measured in 5 experiments

\begin{tabular}{|c|c|c|c|c|}
\hline \multirow[b]{2}{*}{ Pressure } & \multicolumn{2}{|c|}{ Control } & \multicolumn{2}{|c|}{ Tamponade } \\
\hline & Inspiration & $\overline{\text { Expiration }}$ & Inspiration & $\overline{\text { Expiration }}$ \\
\hline & \multicolumn{2}{|c|}{$m m \mathrm{Hg}$} & \multicolumn{2}{|c|}{$m m ~ H g$} \\
\hline Left atrial & +1.9 & +5.1 & +10.8 & +13.4 \\
\hline Pulmonary venous & +3.0 & +7.4 & +10.6 & +16.3 \\
\hline Pericardial & -0.7 & +1.8 & +11.0 & +14.0 \\
\hline Intrathoracic & -5.2 & -1.0 & -4.5 & $\begin{array}{r}714.0 \\
-0.6\end{array}$ \\
\hline Pulmonary venous - left atrial & +1.1 & +2.3 & -0.2 & +2.9 \\
\hline
\end{tabular}

was followed immediately by a period of adjustment and small fall in pressure, and the intrapericardial pressure finally became stable at a level slightly greater than that of control. With increasing degrees of pericardial tamponade, intrapericardial pressure gradually reached levels averaging 11 to $14 \mathrm{~mm} \mathrm{Hg}$. The contour of the intrapericardial pressure tracing, which in the control animal closely resembled the intrathoracic pressure tracing, in the presence of pericardial tamponade showed a disapearance or marked diminution of respiratory fluctuation, and the pressure closely approximated left atrial pressure (Tables I and III, Figure 2). In one experiment in which inspiratory obstruction was used to exaggerate negative pressure ventilation, only minimal fluctuation of intrapericardial pressure was observed despite wide fluctuations of intrathoracic pressure.

Pulmonary venous and left atrial pressures. In the animal with normal respiration and without pericardial tamponade, both pulmonary venous and left atrial pressures fluctuated considerably with respiration (Figure 1). Pulmonary venous pressure was consistently greater than left atrial pressure during all phases of respiration, although

TABLE II

Pressures $(\mathrm{mm} \mathrm{Hg})$ measured without pericardial tamponade during a single experiment

\begin{tabular}{|c|c|c|c|c|c|}
\hline $\begin{array}{l}\text { Breath- } \\
\text { ing }\end{array}$ & $\begin{array}{c}\text { Left } \\
\text { atrial }\end{array}$ & $\begin{array}{l}\text { Pul- } \\
\text { mon- } \\
\text { ary } \\
\text { venous }\end{array}$ & $\begin{array}{l}\text { Peri- } \\
\text { car- } \\
\text { dial }\end{array}$ & $\begin{array}{l}\text { Intratho- } \\
\text { racic }\end{array}$ & $\begin{array}{c}\text { Pul- } \\
\text { mon- } \\
\text { ary } \\
\text { venous- } \\
\text { left } \\
\text { atrial }\end{array}$ \\
\hline Exp. & +5.5 & +8.0 & +4.0 & 0 & +2.5 \\
\hline Insp. & -2.0 & -1.0 & -3.0 & -3.1 & +1.0 \\
\hline Exp. & +4.5 & +7.0 & +1.5 & -0.3 & +2.5 \\
\hline Insp. & -4.5 & -3.5 & -6.0 & -4.0 & +1.0 \\
\hline Exp. & +5.5 & +7.5 & +3.5 & 0 & +2.0 \\
\hline Insp. & +2.5 & +3.5 & +1.0 & -1.1 & +1.0 \\
\hline
\end{tabular}

the gradient from the pulmonary venous to left atrial pressure was maximal during expiration and minimal during inspiration (Tables I and II). This respiratory variation of the magnitude of the gradient between pulmonary venous and left atrial pressures is clearly shown when these two pressures are graphically superimposed (Figure 3). Measurements of pulmonary venous and left atrial pressure during various phases of ventricular systole and diastole indicated that respiratory fluctuation and the relationship between pulmonary venous and left atrial pressure were not altered by the phase of the cardiac cycle.

During pericardial tamponade, left atrial and pericardial pressures usually fluctuated less than pulmonary venous pressure with respiration (Figure 2). In one experiment in which respiration was accentuated by inspiratory obstruction, pulmonary venous pressure showed wide fluctuation with respiration while left atrial pressure remained relatively constant (Figure 4 ). The gradient between pulmonary venous and left atrial pressure was markedly altered during tamponade. Although pulmonary venous pressure continued to exceed left atrial pressure during expiration, dur-

TABLE III

Pressures ( $\mathrm{mm} \mathrm{Hg}$ ) measured with pericardial tamponade during a single experiment

\begin{tabular}{|c|c|c|c|c|c|}
\hline & $\begin{array}{c}\text { Left } \\
\text { atrial }\end{array}$ & $\begin{array}{l}\text { Pul- } \\
\text { monary } \\
\text { venous }\end{array}$ & $\begin{array}{c}\text { Peri- } \\
\text { cardial }\end{array}$ & $\begin{array}{l}\text { Intratho- } \\
\text { racic }\end{array}$ & $\begin{array}{c}\text { Pul- } \\
\text { mon- } \\
\text { ary } \\
\text { venous- } \\
\text { left } \\
\text { atrial }\end{array}$ \\
\hline Insp. & +9.0 & +8.5 & +11.0 & -3.1 & -0.5 \\
\hline Exp. & +14.5 & +16.0 & +18.5 & -0.1 & +1.5 \\
\hline Insp. & +10.0 & $\begin{array}{r}+9.5\end{array}$ & +12.0 & -2.6 & -0.5 \\
\hline Exp. & +14.0 & +16.0 & +18.0 & -0.1 & +2.0 \\
\hline Insp. & +11.0 & +11.0 & +13.0 & -2.1 & 0 \\
\hline Exp. & $\begin{array}{r}+14.5 \\
\end{array}$ & $\begin{array}{r}+15.5 \\
\end{array}$ & +18.0 & -0.3 & +1.0 \\
\hline Insp. & +13.5 & +13.0 & +14.5 & -2.0 & -0.5 \\
\hline Exp. & +12.0 & +13.5 & +16.5 & -0.5 & +1.5 \\
\hline
\end{tabular}




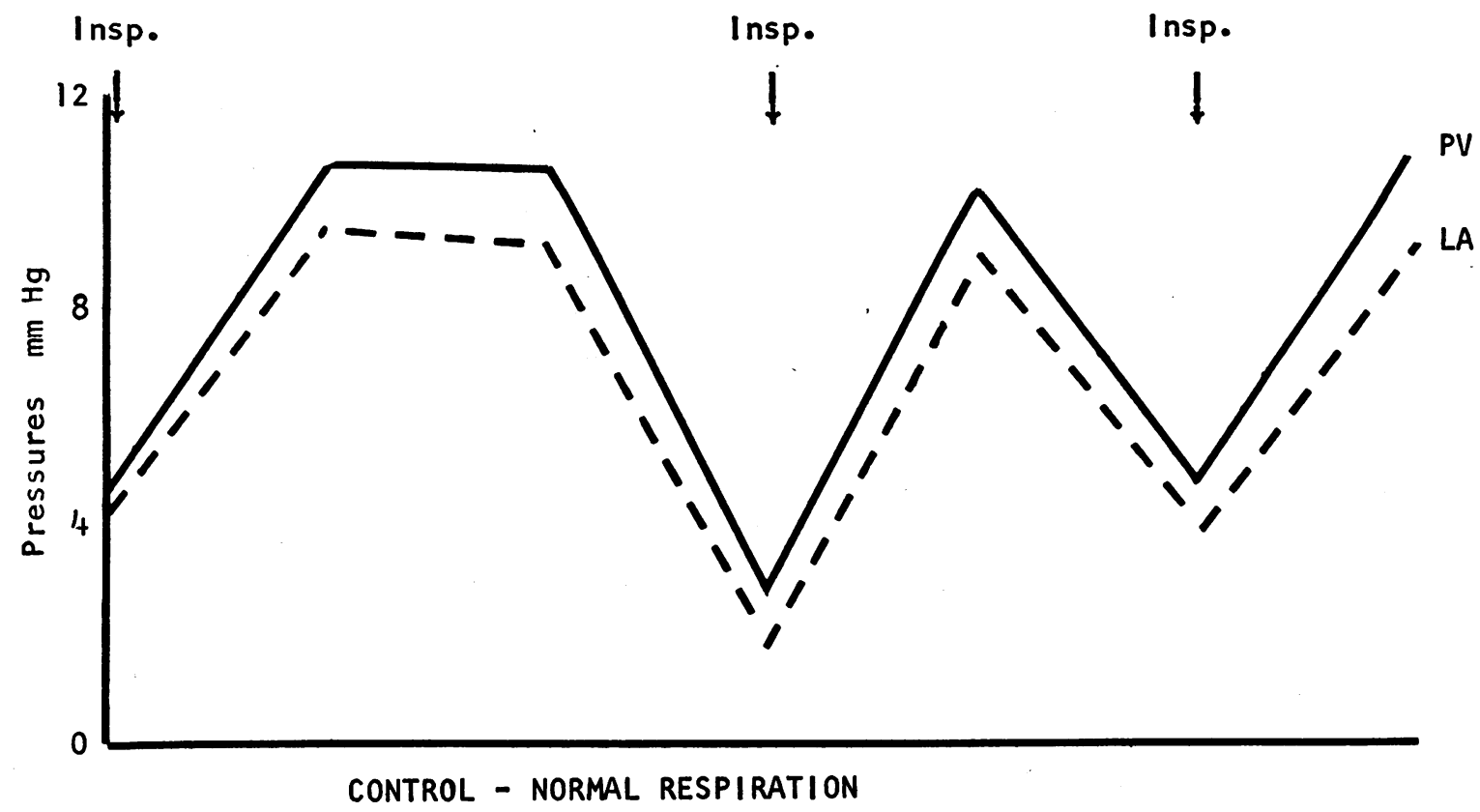

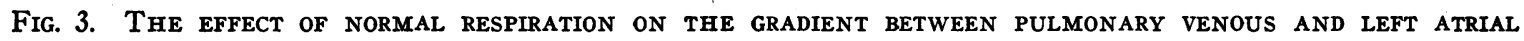
PRESSURES IN THE CONTROL ANIMAL.

ing inspiration it usually was equal to or below left atrial pressure. 'This resulted in a negative or reversed gradient between pulmonary venous and left atrial pressure during inspiration (Tables I and III). These relationships are clearly shown in Figures 4 and 5 , in which pulmonary venous and left atrial pressures are graphically superimposed. Figure 2 shows how pulmonary venous pressure was affected by intrapleural pressure, whereas left atrial pressure followed intrapericardial pressure during tamponade.

Cineangiograms. In the control animal, when iodinated oil was injected into the inferior vena

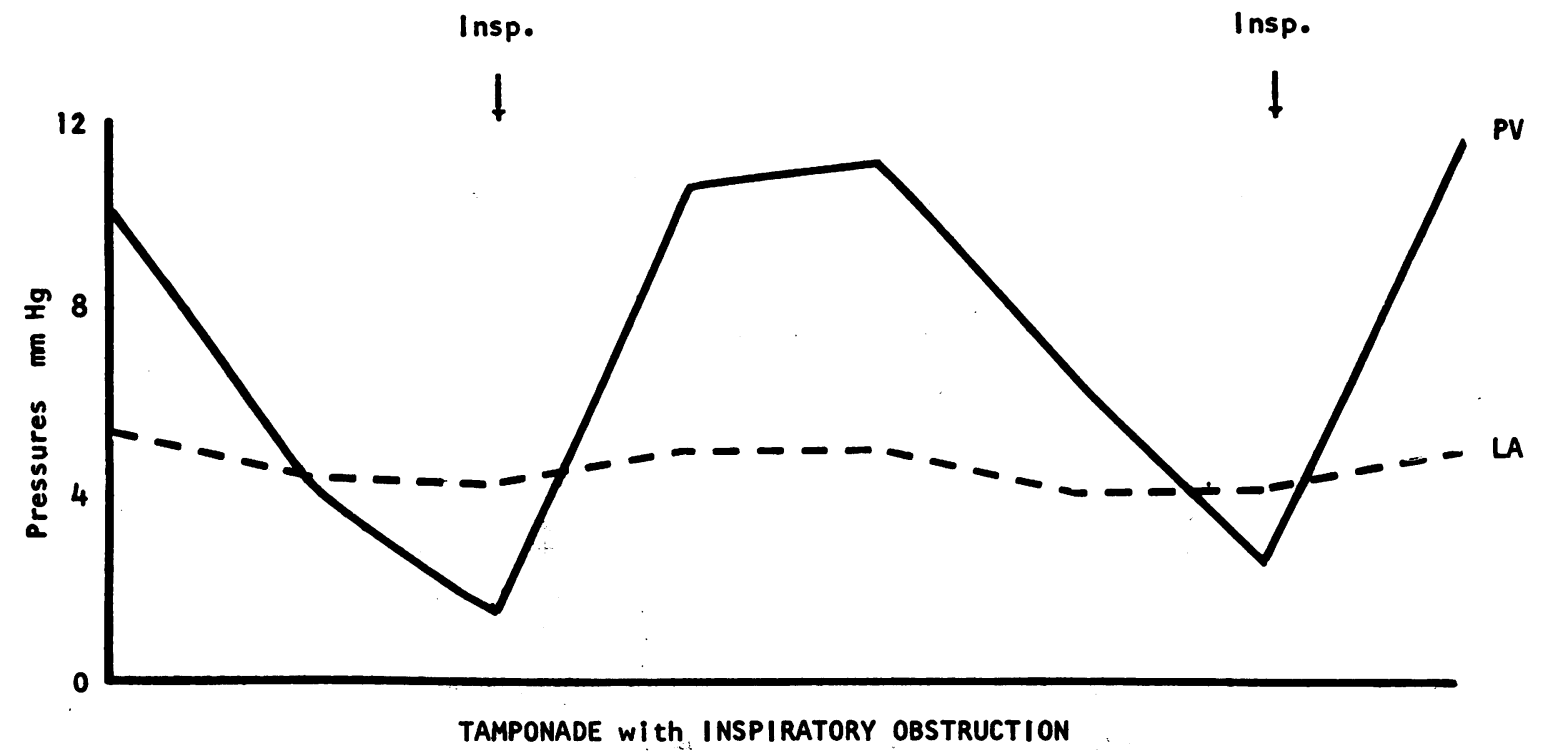

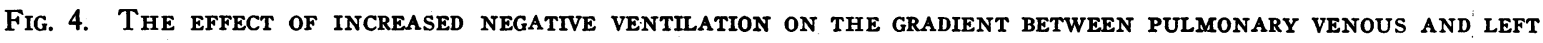
ATRIAL PRESSURE DURING PERICARDIAL TAMPONADE. 


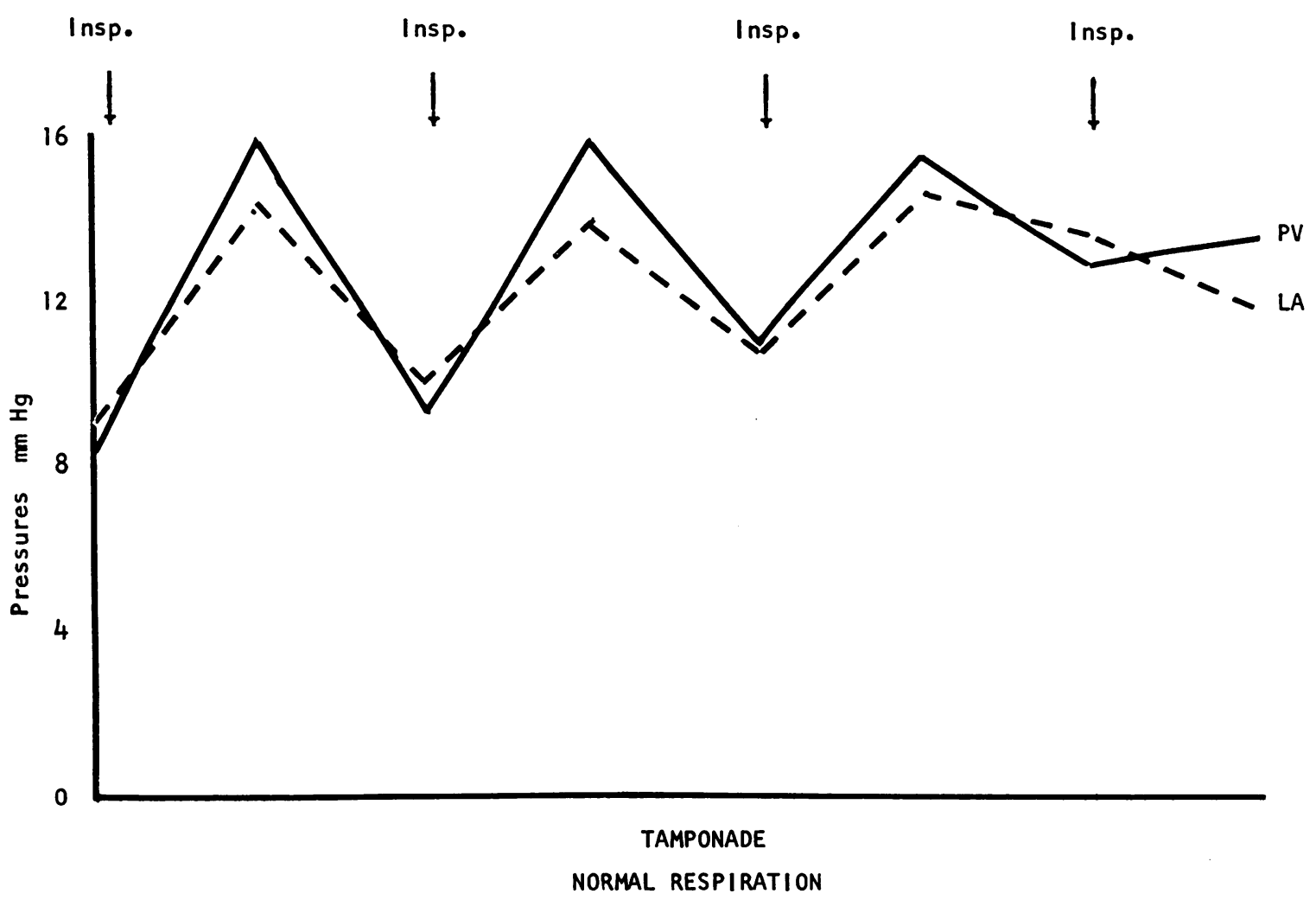

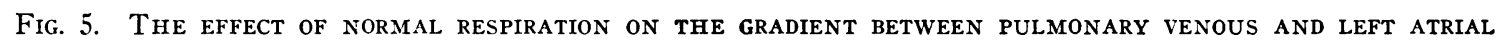
PRESSURE DURING PERICARDIAL TAMPONADE.

cava, the droplets moved towards the right atrium during all phases of respiration, but with maximal velocity during inspiration. During injection into the left upper pulmonary vein, the droplets moved towards the left atrium during all phases of respiration, but with maximum velocity during expiration. After production of pericardial tamponade and in the presence of pulsus paradoxus, the movement of the droplets in the inferior vena cava was reduced during all phases of respiration, but during expiration it was almost halted or actually reversed (Figure 6). The movement of the oil droplets in the pulmonary vein was also slowed during all phases of respiration. Whereas maximal forward velocity occurred with expiration, however, there was now marked decrease in forward movement of the droplets during inspiration, and actual retrograde movement was observed in some instances.

In one instance, a large amount of opaque oil was injected into the left atrium during pericardial tamponade. A large globule of oil remained in the left atrium after the injection was completed, allowing the effects of respiration on pulmonary venous flow to be clearly observed. During expiration the globule was located entirely within the left atrium, but with inspiration there was a marked retrograde movement of the opaque material into the pulmonary veins, extending even into the major tributaries (Figure 7). This provided conclusive evidence of reversal of pulmonary venous flow during inspiration.

\section{DISCUSSION}

The results of the present study indicate that an abnormal gradient between pulmonary venous and left atrial pressure is the major underlying hemodynamic alteration responsible for pulsus paradoxus. Katz and Gauchat (3) in 1924 first suggested that the marked inspiratory fall in systemic arterial pressure observed during tamponade was related to reduced filling of the left ventricle. This was based entirely on indirect evidence resulting from observations of measured pressure gradients between superior vena cava and right atrium. These authors noted that during tamponade the pressure gradient between the superior 
vena cava and the right atrium was reduced during inspiration. This finding, coupled with the observation that during tamponade the respiratory fluctuations of intrapericardial pressure disappeared, suggested to them that intrathoracic pressure was not equally transmitted to intrapericardial and extrapericardial structures, in the presence of pericardial tamponade. They postulated that this reduction of the gradient between the filling veins and the right heart probably also occurred between the pulmonary veins and the left heart. Thus, reduced filling of the left ventricle during inspiration might occur and would then result in a lowered left ventricular stroke output and systemic arterial pressure.

During a study of experimental tamponade, Isaacs, Berglund, and Sarnoff (6) measured gra- dients between pulmonary venous and left atrial pressures, but failed to demonstrate any significant gradient. Since their study was performed in the open-chest animal maintained on positive-pressure breathing, it does not apear to have any direct application to the present discussion. More recently, Sharp and co-workers (4) studied the hemodynamic effects of induced cardiac tamponade in man. They were able to study the relationship of pulmonary arterial wedge pressure to intrapericardial pressure during varying degrees of pericardial tamponade. Their data indicated that the filling gradient of the left ventricle was reduced during inspiration, thus corroborating the hypothesis suggested by Katz and Gauchat some years earlier. Their data, however, were based on measurements of pulmonary artery wedge and
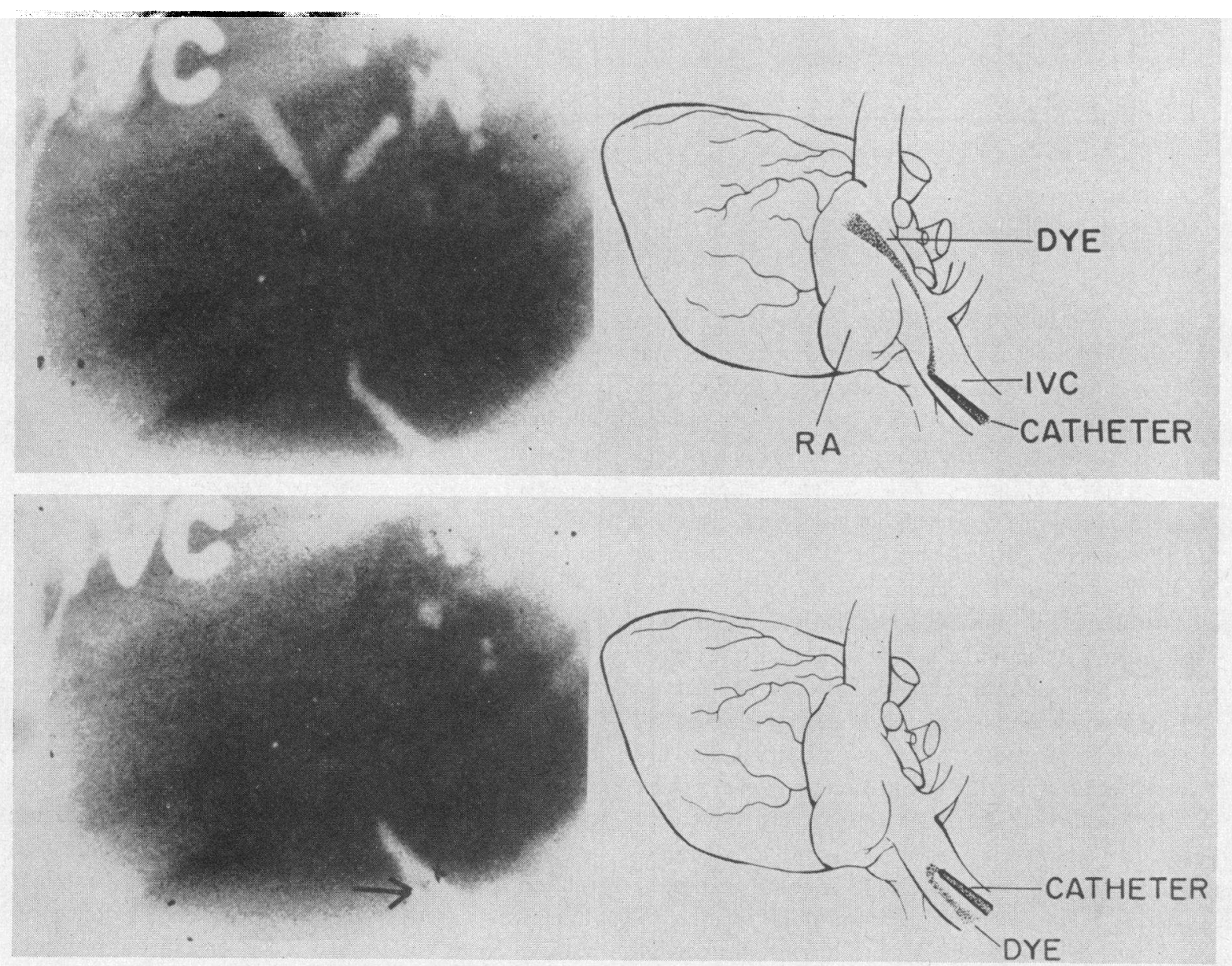

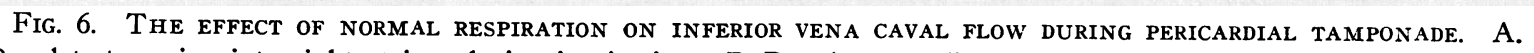
Droplet streaming into right atrium during inspiration. B. Droplet extending retrograde in the inferior vena cava during expiration. 

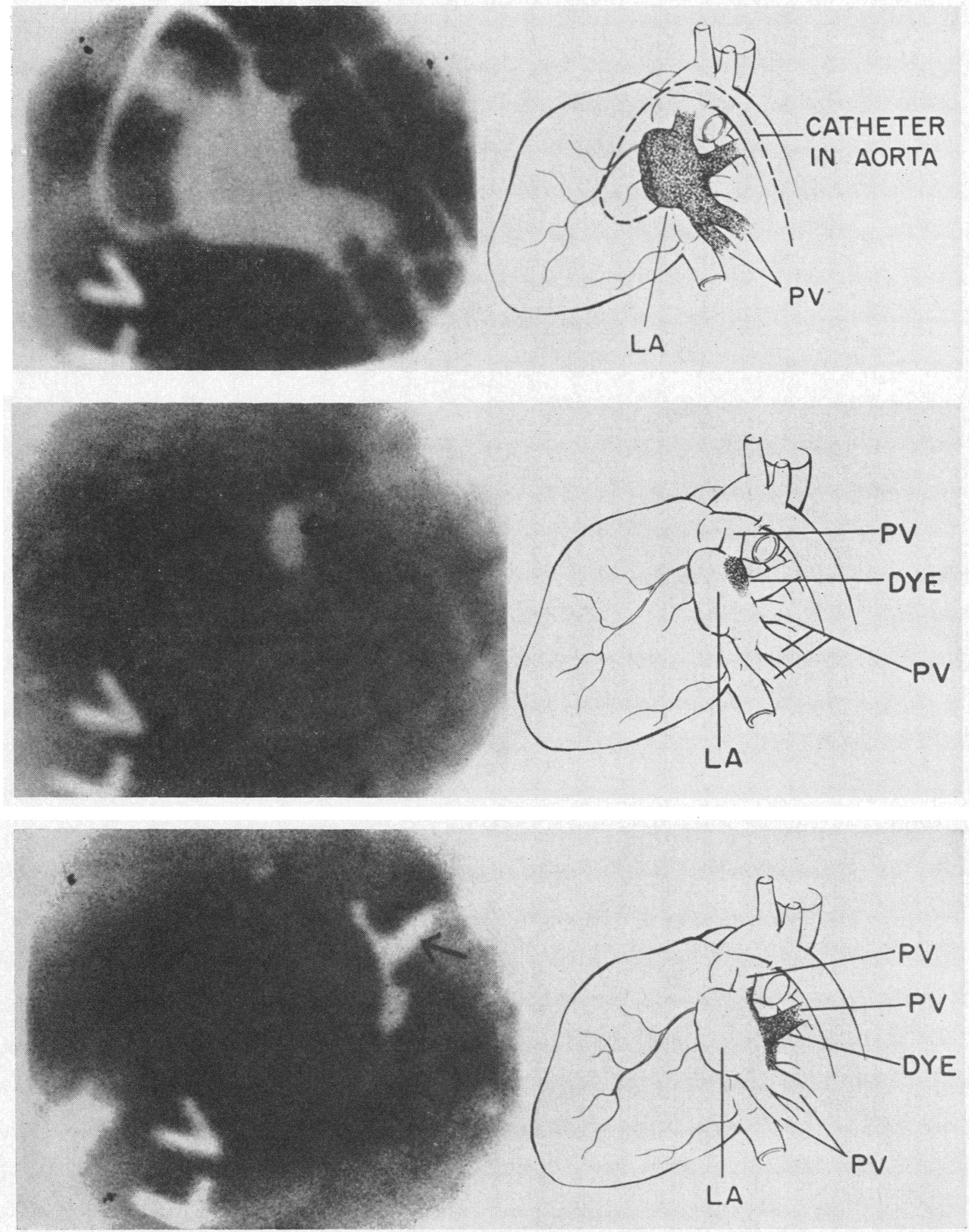

Fig. 7. The efFect of NORMal Respiration on pUlmonary venous flow during pericardial tamponade. A. Left atrium and pulmonary veins during injection of opaque material into the left atrium. B. Retained globule within the left atrium during expiration. C. Retained globule extending retrograde into pulmonary veins during inspiration. 
intrapericardial pressures, and actual pulmonary venous and left atrial pressures were not measured.

The present study offers direct evidence that the mechanism for pulsus paradoxus resides in the altered relationship between pulmonary venous and left atrial pressure during the respiratory cycle. Normally, the variations in intrathoracic pressures are well transmitted to the pericardial space. Even under normal conditions, however, the intrathoracic pressure changes do not equally affect left atrial and pulmonary venous pressures so that there is a small reduction in the gradient between pulmonary venous and left atrial pressure during inspiration. This would interfere with left atrial and left ventricular filling and would explain the lowered left ventricular ejection and systemic arterial pressure observed during inspiration under normal conditions. During pericardial tamponade, the fluid under high pressure in the pericardial space interferes markedly with transmission of the negative pressure to the left atrium during inspiration. During tamponade, left atrial pressure tends to follow intrapericardial pressure rather than intrathoracic pressure, while pulmonary venous pressure continues to show wide fluctuations with changes in intrathoracic pressure. Thus during inspiration a disproportionate fall in pulmonary venous pressure may occur as compared to left atrial pressure, resulting in a fall or actual reversal of the normal filling gradient of the left atrium. This interferes with left atrial and left ventricular filling even more than usual during inspiration, exaggerating the normal drop in left ventricular stroke volume and systemic arterial pressure.

In several instances where the degree of pericardial tamponade was extreme and systemic pressure markedly reduced, the pulsus paradoxus disappeared. This might have been due to reduction of the total cardiac output. Another possible explanation, however, might be that as the pulmonary veins became more and more distended they lost their capacity to expand further in response to changes in intrathoracic pressure.

An interesting concept relating to mechanics of left ventricular filling is presented in this study. In some experiments, a constant level of left atrial pressure was observed throughout the respiratory cycle during pericardial tamponade. Despite this constant filling pressure of the left ventricle, there was a marked variation in its stroke output. It is possible that very minor differences in filling pressure, not measurable by the methods used, could account for these observations. The phenomenon could also be explained on the basis of a different effective compliance of the left atrial and ventricular walls during tamponade. In the normal animal, filling of the left ventricle will depend on the filling pressure and the compliance of the wall. During tamponade, a constant external pressure is applied to the ventricle, markedly limiting its distensibility. During diastole there is direct communication between the left ventricle, left atrium, and pulmonary veins. The amount of blood flow from left atrium into left ventricle may therefore be influenced by retrograde flow into the pulmonary veins. Thus even in the face of a constant left atrial pressure, occasioned by the constant external pressure from the pericardial sac, the flow from left atrium into left ventricle, and hence left ventricular volume in diastole, may vary. During inspiration, when pulmonary venous pressure falls below left atrial and intrapericardial pressure and retrograde flow into the pulmonary veins occurs, left ventricular filling may be reduced. During expiration, when pulmonary venous pressure exceeds left atrial pressure, greater filling of the left ventricle may occur.

It is interesting that the cineangiogram studies we conducted suggest that maximal filling of the right atrium during tamponade occurs during inspiration. Katz and Gauchat (3), on the other hand, from their measurements of gradients between superior vena caval and right atrial pressures, indicated that maximal filling of the right atrium would occur during expiration when the gradient is most favorable. A possible explanation for this difference seems to rest in the nature of the superior vena cava as an intrathoracic but extrapericardial vessel, subjected to respiratory fluctuations similar to those of the pulmonary veins. The inferior vena cava, on the other hand, is largely extrathoracic and during tamponade would not be subjected to the same extent to changes in intrathoracic pressure. Brecher (7) has in fact shown that inferior vena caval pressure actually increases during inspiration owing to descent of the diaphragm and the pressure exerted on it. 


\section{SUMMARY}

The mechanism responsible for the increased respiratory variation of systemic arterial pressure during pericardial tamponade (pulsus paradoxus) was studied in the closed-chest animal. Simultaneous measurements of pulmonary venous, left atrial, left ventricular, intrapericardial, and intrathoracic pressures were made during varying degrees of pericardial tamponade, and the effects of both normal ventilation and increased negative ventilation observed. Pulmonary venous and inferior vena caval flow rates were studied by cineangiography.

Results indicate that a disturbance of the gradient between pulmonary venous and left atrial pressures is the fundamental circulatory defect responsible for the exaggerated respiratory variation in pulse, characteristic of pericardial tamponade. In pericardial tamponade, pulmonary venous pressure follows intrathoracic pressure, whereas left atrial pressure follows intrapericardial pressure, resulting in a marked reduction or actual reversal of the gradient between pulmonary venous and left atrial pressure during inspiration. This interferes with left ventricular filling even more than usual during inspiration, exaggerating the decrease in left ventricular stroke volume and the fall in systemic arterial pressure. This hypothesis was further confirmed by the cineangiograms, which demonstrated reversal of flow in the pulmonary veins during inspiration in pericardial tamponade.

\section{REFERENCES}

1. Wood, P. Diseases of the Heart and Circulation, 1st ed. London, J. B. Lippincott, 1952.

2. Dornhorst, A. C., Howard, P., and Leathart, G. L. Pulsus paradoxus. Lancet, 1952, 262, 746.

3. Katz, L. N., and Gauchat, H. W. Observations on pulsus paradoxus (with special reference to pericardial effusions): II. Experimental. Arch. intern. Med. 1924, 33, 371.

4. Sharp, J. T., Bunnell, I. L., Holland, J. F., Griffith, G. T., and Greene, D. G. Hemodynamics during induced cardiac tamponade in man. Amer. J. Med. 1960, 29, 640.

5. Kinsman, J. M., Moore, J. W., and Hamilton, W. F. Studies on the circulation. I. Injection method: physical and mathematical considerations. Amer. J. Physiol. 1929, 89, 322.

6. Isaacs, J. P., Berglund, E., and Sarnoff, S. J. Ventricular function. III. The pathologic physiology of acute cardiac tamponade studied by means of ventricular function curves. Amer. Heart J. 1954, 48, 66.

7. Brecher, G. A. Venous Return. New York, Grune \& Stratton, 1956. 